\title{
Laparoscopic Splenectomy Alone for Sickle Cell Disease \\ Account of 50 paediatric cases
}

Zainab N. Al-Balushi, ${ }^{1}$ Khalid M. Bhatti, ${ }^{1}$ Muhammad T. Ehsan, ${ }^{1}$ Yousuf Al-Shaqsi, ${ }^{1}$ Nawal A. R. Al-Sharji, Hatem A. A. Mady, ${ }^{2}$ Mahmoud H. Sherif ${ }^{1}$

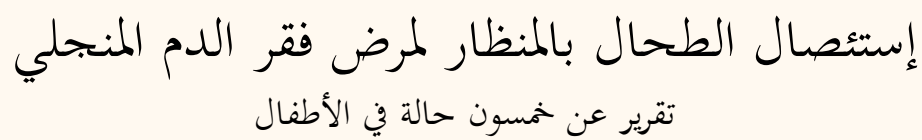

زينب ناصر البلوشية، خالد منير بهاتي، محمد إحسان توفيق، يوسف الشقصي، نوال عبداله راشد الثرجية، حاتم علي ماضي، محمود حاتم شريف

ABSTRACT: Objectives: In Oman, the most frequent indication for a splenectomy in children is sickle cell disease (SCD), which is one of the most common haematological disorders in the Gulf region. This study aimed to describe paediatric laparoscopic splenectomies alone for SCD at a tertiary hospital in Oman. Methods: This study was conducted between February 2010 and October 2015 at the Sultan Qaboos University Hospital, Muscat, Oman. The medical records of all children aged $\leq 15$ years old undergoing splenectomies during the study period were reviewed. Results: A total of 71 children underwent laparoscopic splenectomies during the study period; of these, 50 children (28 male and 22 female) underwent laparoscopic splenectomies alone for SCD. The children's weight ranged between 11-43 kg. The most common indication for a splenectomy was a recurrent splenic sequestration crisis (92\%). Surgically removed spleens weighed between $155-1,200 \mathrm{~g}$ and measured between $9-22 \mathrm{~cm}$. Operative times ranged between 66-204 minutes and intraoperative blood loss ranged between 10-800 mL. One patient required conversion to an open splenectomy. Postoperative complications were noted in only four patients. The median hospital stay duration was three days. Conclusion: Among this cohort, the mean operating time was comparable to that reported in the international literature. In addition, rates of conversion and postoperative complications were very low. These findings indicate that a laparoscopic splenectomy alone in paediatric patients with SCD is a feasible option.

Keywords: Laparoscopy; Splenectomy; Pediatrics; Sickle Cell Disease; Oman.

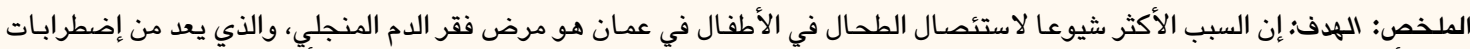

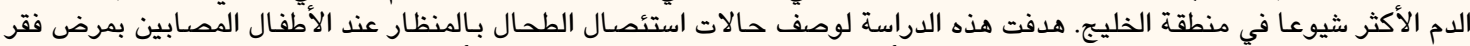

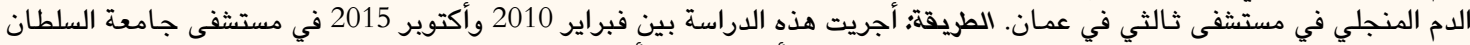

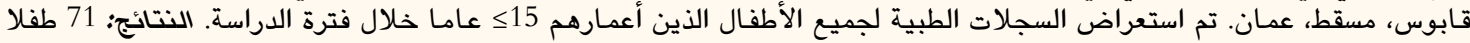

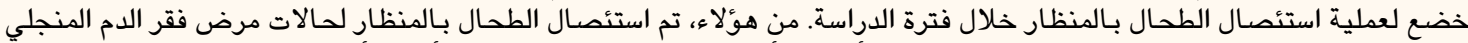

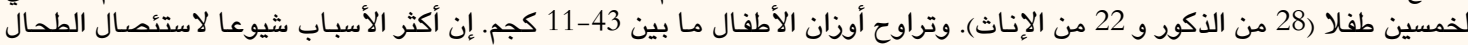

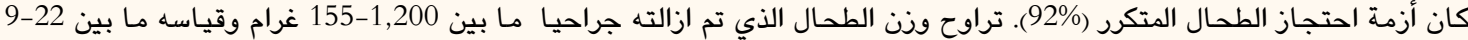

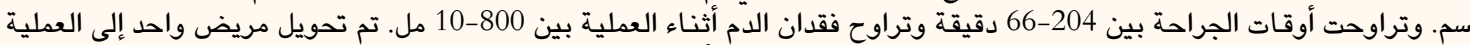

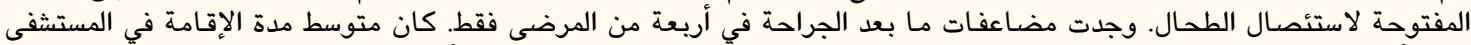

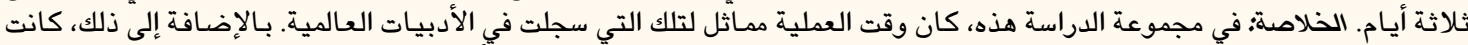

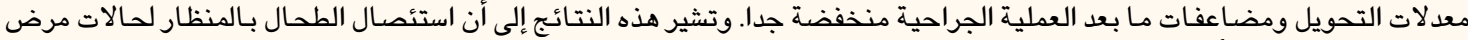

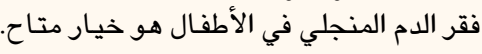

$$
\text { الكلمـات المفتاحية: تنظير البطن؛ استئصسال الطحال؛ طب الأطفال؛ مرض فقر الدم الدنجلي؛ عمان. }
$$

\footnotetext{
AdVANCES IN KNOWLEDGE

This study describes the results of laparoscopic splenectomies alone in a cohort of Omani children with sickle cell disease (SCD).

To the best of the authors' knowledge, this study is the first of its kind in the region and the only one to exclude splenectomies performed for other haematological indications or combined with other procedures.
}

\section{Application to Patient Care}

The findings of the current study indicate that a laparoscopic splenectomy alone for paediatric patients with SCD is a safe and acceptable procedure. 
$\mathrm{H}$ AEMATOLOGICAL INDICATIONS FOR A splenectomy vary globally. In the Western world, the most common indications for a splenectomy in children are hereditary spherocytosis and idiopathic thrombocytopaenic purpura. $^{1-4}$ In Oman, the most common indication for a splenectomy in children is sickle cell disease (SCD). ${ }^{5}$ This haematological disorder is one of the most prevalent in the Gulf region, with an incidence of one in 323 live births and a prevalence of $5.8 \% .^{6-8}$

The management of paediatric patients with SCD can be challenging, as surgical procedures may precipitate a sickling crisis. ${ }^{9}$ Paediatric SCD patients may require a splenectomy for various indications, such as recurrent splenic sequestration or splenic dysfunction. ${ }^{10}$ The effectiveness of splenectomies in improving haematological outcomes is well-established. ${ }^{11,12}$ However, most studies in the medical literature combine the results of laparo-scopic splenectomies carried out for various indications such as hereditary spherocytosis, idiopathic thrombocytopaenic purpura or chronic myelomonocytic leukaemia, with only a small number focusing solely on laparoscopic splenectomies among patients with SCD. ${ }^{1,3,4}$ Moreover, some researchers include children who undergo a combined laparoscopic cholecystectomy and splenectomy. ${ }^{3}$ Hence, there is a lack of research describing the results of laparoscopic splenectomies alone among children with SCD.

This study aimed to describe the results of laparoscopic splenectomies alone among a cohort of children with SCD. To the best of the authors' knowledge, this is the first study of its kind to analyse laparoscopic splenectomies due to SCD alone, excluding splenectomies performed as a result of other haematological disorders or combined with other surgical procedures.

\section{Methods}

This retrospective study was conducted at the Sultan Qaboos University Hospital (SQUH), Muscat, Oman. A review of all patients $\leq 15$ years old undergoing a laparoscopic splenectomy alone for SCD between February 2010 and October 2015 was undertaken. Patients who were operated upon for other haematological diseases or who underwent splenectomies combined with other procedures (e.g. a cholecystectomy) were excluded. The study was retrospective for the first three years of data collection but was then maintained prospectively.

The medical records of the patients were reviewed for the following information: demographic characteristics; indications for the splenectomy; operative time; preoperative and postoperative transfusion requirements; intraoperative complications or blood loss; the need for conversion to open surgery; postoperative complications (including acute chest syndrome [ACS], vaso-occlusive crises and general/ wound infections); administration of narcotic analgaesia; and length of hospital stay. ACS was diagnosed according to previously described criteria. ${ }^{9}$

Indications for splenectomies alone in children with SCD included either hypersplenism or acute splenic sequestration. Hypersplenism was defined as splenic enlargement with one of the following conditions: anaemia (requiring a transfusion of packed red blood cells exceeding $250 \mathrm{~mL} / \mathrm{kg}$ per year); thrombocytopaenia (indicated by a platelet count of $\leq 100,000 / \mathrm{mm}^{3}$ ); and neutropaenia (indicated by a white blood cell count of $\left.\leq 4,000 / \mathrm{mm}^{3}\right) .{ }^{13}$ Children were considered to have acute splenic sequestration if they suffered from at least one major or two minor attacks. Major attacks were characterised by a combination of splenic enlargement, a $2-3 \mathrm{~g} / \mathrm{dL}$ drop in haemoglobin $(\mathrm{Hb})$ levels and associated hypovolemia while minor attacks constituted splenic enlargement and a drop in $\mathrm{Hb}$ levels only, without hypovolemia. ${ }^{12}$

Laparoscopic splenectomies were performed according to the following procedure. Preoperatively, all patients received a pneumococcal polyvalent vaccine at least two weeks before the surgery. In addition, ultrasonography scans were performed to determine the size of the spleen and to rule out the presence of concomitant gallstones. Patients were transfused preoperatively if their $\mathrm{Hb}$ levels were $<10 \mathrm{~g} / \mathrm{dL}$. In the operating theatre, patients were placed in a semi-decubitus position with their left side elevated. ${ }^{3,5,14}$ A total of $25 \mathrm{mg} / \mathrm{kg}$ of cefuroxime was administered as an induction dose. The positioning of the ports during the splenectomy is shown in Figure 1. Maryland forceps

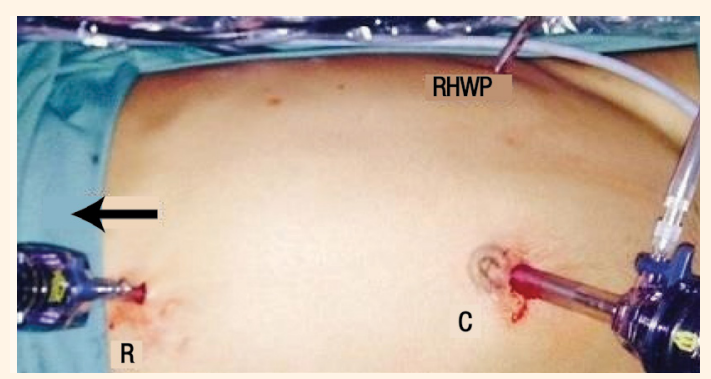

Figure 1: Photograph showing the positioning of ports during a laparoscopic splenectomy alone for sickle cell disease. The child is lying in a semi-decubitus position with the arrow pointing towards the head. Note the placement of the camera port $(C)$, retraction port $(R)$ in the epigastrium and right hand working port (RHWP) in the left iliac fossa. 
(Olympus Medical Systems, Tokyo, Japan) were used to isolate the splenic vessels where needed while a harmonic scalpel (HARMONIC ${ }^{\circledR}$ Shears, Ethicon Endo-Surgery Inc., Blue Ash, Ohio, USA) was used to control the hilar vessels and divide the ligaments supporting the spleen. All patients underwent total splenectomies as there is currently a lack of evidence regarding the benefits of partial splenectomies in improving SCD haematological parameters; moreover, partial splenectomies are associated with greater intraoperative blood loss and higher rates of conversion to open surgery. ${ }^{14,15}$ Postoperatively, patients were managed by a physician specialising in paediatric haematology. One month after discharge, the patients were followed-up in the paediatric surgery outpatient department.

Ethical approval for this study was received from the Medical Research \& Ethics Committee of the College of Medicine \& Health Sciences at Sultan Qaboos University (MREC \#396).

\section{Results}

A total of 71 children underwent laparoscopic splenectomies during the study period. Of these, 18 patients were excluded because they underwent laparoscopic cholecystectomies combined with splenectomies and three patients were excluded because they had haematological disorders other than SCD. As such, a total of 50 paediatric patients (28 male and 22 female) underwent splenectomies alone for SCD. The most common reason splenectomies were performed was due to a recurrent splenic sequestration crisis (92\%). Most of the children were $\leq 5$ years old $(60 \%)$.

The mean age of the patients was $6.00 \pm 2.76$ years (range: 2-15 years old) and their mean weight was $18.66 \pm 6.84 \mathrm{~kg}$ (range: 11.2-43.0 kg). The mean operative time was $119.66 \pm 30.39$ minutes (range: 66-204 minutes). The mean intraoperative blood loss was $94.80 \pm 148.64 \mathrm{~mL}$ (range: $10-800 \mathrm{~mL}$ ). The median hospital stay duration was three days. The mean weight of removed spleens was $457.76 \pm 178.88 \mathrm{~g}$ (range: $155-1,200 \mathrm{~g}$ ) while the mean size of the spleens was $13.62 \pm 3.39 \mathrm{~cm}$ (range: $9-22 \mathrm{~cm}$ ) [Table 1]. The mean size of the spleen in patients $\leq 5$ years old was lower than that of patients $>5$ years old $(12.56 \pm 2.66$ $\mathrm{cm}$ versus $15.22 \pm 3.79 \mathrm{~cm} ; P=0.026)$. However, mean weight did not vary significantly between patients $\leq 5$ years old and those $>5$ years old $(450.00$ g versus 469.00 g, respectively; $P=0.820$ ).

Five patients required intraoperative blood transfusions while five patients were transfused postoperatively. Narcotic analgaesia was administered

Table 1: Descriptive characteristics of paediatric laparoscopic splenectomies alone for sickle cell disease conducted at the Sultan Qaboos University Hospital, Muscat, Oman (N = 50)

\begin{tabular}{|c|c|c|c|}
\hline Characteristic & Range & Median & Mean \pm SD \\
\hline Patient age in years & $2-15$ & 5 & $6.00 \pm 2.76$ \\
\hline Patient weight in kg & $11.2-43.0$ & 16.7 & $18.66 \pm 6.84$ \\
\hline Size of spleen in $\mathrm{cm}$ & $9.0-22.0$ & 12.4 & $13.62 \pm 3.39$ \\
\hline $\begin{array}{l}\text { Weight of spleen } \\
\text { in g }\end{array}$ & $155-1,200$ & 485 & $457.76 \pm 178.88$ \\
\hline $\begin{array}{l}\text { Operating time in } \\
\text { minutes }\end{array}$ & $66-204$ & 120 & $119.66 \pm 30.39$ \\
\hline $\begin{array}{l}\text { Operative blood } \\
\text { loss in } \mathrm{mL}\end{array}$ & $10-800$ & 50 & $94.80 \pm 148.64$ \\
\hline Hospital stay in days & $1-55$ & 3 & $4.38 \pm 7.57$ \\
\hline
\end{tabular}

$S D=$ standard deviation .

to 12 patients (24\%). There were seven cases of postoperative complications occurring in four patients, including ACS $(n=4 ; 8 \%)$, general infections $(\mathrm{n}=2 ; 4 \%)$ and acute pancreatitis $(\mathrm{n}=1 ; 2 \%)$. [Table 2]. The patient with acute pancreatitis had received an injury to the tail of the pancreas and was diagnosed on the $10^{\text {th }}$ postoperative day when high amylase levels were noted in the drained fluid. The same patient also developed ACS and remained in the hospital for 55 days. Septic episodes were noted in two patients (4\%) and the blood culture of one patient tested positive for Salmonella. These patients required intravenous antibiotics (90 $\mathrm{mg} / \mathrm{kg}$ of intravenous piperacillin/ tazobactam every 8 hours) for an average of 12 days.

Table 2: Frequency of intraoperative and postoperative variables of paediatric laparoscopic splenectomies alone for sickle cell disease conducted at the Sultan Qaboos University Hospital, Muscat, Oman ( $=50)$

$\begin{array}{lc}\text { Variable } & \mathbf{n}(\%) \\ \text { Blood transfusions } & \mathbf{1 0}(\mathbf{2 0}) \\ \quad \text { Intraoperative } & 5(10) \\ \quad \text { Postoperative } & 5(10) \\ \text { Conversion to open surgery } & \mathbf{1}(2) \\ \text { Narcotic analgaesia administration } & \mathbf{1 2}(\mathbf{2 4 )} \\ \text { PICU admissions } & \mathbf{2 ( 4 )} \\ \text { Postoperative complications } & 7(\mathbf{1 4}) \\ \quad \text { Acute pancreatitis } & 1(2) \\ \quad \text { Acute chest syndrome } & 4(8) \\ \quad \text { General infections } & 2(4) \\ \quad \text { Wound infections } & 0(0) \\ \quad \text { Vaso-occlusive crisis } & 0(0) \\ \text { Mortality } & \mathbf{0}(0) \\ P I C U=\text { paediatric intensive care unit. } & \end{array}$


Only one patient required conversion to open surgery due to intractable intraoperative bleeding requiring both intra- and postoperative transfusions. This patient was kept under observation in the Paediatric Intensive Care Unit for 48 hours. In two other patients, a small incision was made in the lower quadrant to remove the spleen. The mean duration of follow-up with paediatric haematologists was $27.00 \pm 21.20$ months (range: $1-69$ months; median: 18 months).

\section{Discussion}

To the best of the authors' knowledge, this singlecentre study is the first of its kind in the region describing the results of laparoscopic splenectomies in paediatric patients with SCD. In the current study, the most common indication for a splenectomy was an acute splenic sequestration crisis; the percentage of children requiring a splenectomy for this indication (92\%) is higher than that reported in any other study in the literature to date. ${ }^{2,13,16,17}$ This may be due to early diagnosis or increased acceptance of a laparoscopic approach among family members or caregivers. However, $60 \%$ of the children who underwent laparoscopic splenectomies in the present study were under fiveyears old, which is the most commonagefor an acute splenic sequestration crisis. ${ }^{10}$ As sequestration is rare beyond this age, it seems likely that some patients required a splenectomy for some other reason.

Splenectomies can be performed either using an open or laparoscopic technique. ${ }^{11,12}$ Many researchers have reported that a laparoscopic procedure is the superior choice. ${ }^{1,12,14}$ Reported advantages include minimal trauma during access, enhanced cosmetic results, reduced pain and a shorter hospital stay. ${ }^{1-3}$ Moreover, there is a reduced incidence of ACS following a laparoscopic splenectomy compared to the open procedure; this can be attributed to several factors, including the decreased risk of pulmonary fat embolisms and wound infection and a lower incidence of hypoventilation due to reduced postoperative pain. ${ }^{11}$ Nevertheless, conversion to an open splenectomy may be needed during a laparoscopic splenectomy due to intractable bleeding, adhesion of the spleen, anatomical variations and difficulties in removing the spleen. ${ }^{3}$ In the current study, the conversion rate was very low (2\%); conversion rates in the literature vary from $0-18 \%{ }^{3}$

The dissection of the hilar vessels is an important aspect of a laparoscopic splenectomy; to this end, various dissections tools are available, including linear staplers and clipping and harmonic devices. ${ }^{1,3,4,14}$ Although it shortens the operative time, en bloc stapling of the hilum can increase the risk of the patient developing arteriovenous fistulae, injuries to the pancreatic tail and splenic or portal vein thrombosis. ${ }^{4}$ In a small study of 17 patients, Vargün et al. established a one-year follow-up as a safe period of time for evaluation following en bloc stapling; however, this procedure has not yet been adopted at SQUH. ${ }^{4,5}$ In the current study, the splenic hila were handled with Maryland forceps (Olympus Medical Systems) for isolation and an ultrasonic harmonic scalpel was used to seal and divide the vessels. The efficacy of ultrasonic shear coagulation has been previously documented by Schaarschmidt et al. ${ }^{18}$

During splenectomies, the length of operative time depends on many factors, including the choice of instrument for hilar dissection and the experience of the surgeon. ${ }^{4,5,19-21}$ In the current study, the mean operative time was 119 minutes. This is comparable to times reported in the international literature which record a mean operative time of 107 minutes for en bloc stapling, 130 minutes using the LigaSure ${ }^{\mathrm{TM}}$ Vessel Sealing System (Medtronic, Minneapolis, Minnesota, USA) and 150 minutes for individual ligation., ${ }^{4,20}$ However, it is important to note that the mean operative time decreases over the years as surgeons become more experienced. ${ }^{5,21}$

Among postoperative complications, ACS is the most disease-specific in that the complication is caused by the underlying SCD rather than the procedure. In a recent retrospective study, Bonnard et al. reported the incidence of ACS following a laparoscopic splenectomy to be $23 \% .^{9}$ In the present study, the incidence of ACS was much lower (8\%). Other serious postoperative complications include pancreatitis due to an injury to the tail of the pancreas during a laparoscopic splenectomy, with a reported incidence of up to $15 \% .{ }^{4}$ In the current study, only one patient (2\%) received an injury to the tail of the pancreas. Moreover, none of the patients developed wound infections, overwhelming post-splenectomy infections (OPSIs), portal or splenic vein thrombosis or visceral injuries. These findings indicate that a laparoscopic splenectomy alone in paediatric patients with SCD is a safe and feasible surgical approach.

The current study had several limitations. This was a descriptive study and lacked a comparison of laparoscopic and open splenectomy techniques. However, the superiority of a laparoscopic approach over an open technique has been previously wellestablished. ${ }^{1-3,12,14}$ Nevertheless, this study presents only the results of laparoscopic surgeries for patients with a single haematological condition; hence, the results should be interpreted carefully. Studies documenting the quality of life of SCD patients and 
their long-term outcomes should be conducted in order to determine the efficacy of a laparoscopic splenectomy in improving blood counts and reducing the risk of acute splenic sequestration, blood transfusion requirements and the incidence of ACS and OPSIs. Moreover, children with SCD from the Gulf region have been reported to have persistent splenomegaly later in life ( $\geq 18$ years old), possibly due to high fetal $\mathrm{Hb}$ levels. ${ }^{16}$ In the current study, fetal $\mathrm{Hb}$ levels were not recorded; however, it was noted that spleens were larger among older patients $>5$ years old. Future qualitative studies should therefore explore this issue in greater detail.

\section{Conclusion}

Among the studied children with SCD, the most common indication for a laparoscopic splenectomy was recurrent splenic sequestration. A low conversion rate to open surgery was noted and very few patients suffered from postoperative complications. These findings indicate that a laparoscopic splenectomy alone is a safe and feasible approach for paediatric patients with SCD.

\section{ACKNOWLEDGEMENTS}

The authors would like to thank the Department of Haematology at SQUH, who played a vital role in preand postoperative patient management, diagnosis and establishing indications for splenectomies.

\section{CONFLICT OF INTEREST}

The authors declare no conflicts of interest.

\section{FUNDING}

No funding was received for this study.

\section{References}

1. Curran TJ, Foley MI, Swanstrom LL, Campbell TJ. Laparoscopy improves outcomes for pediatric splenectomy. J Pediatr Surg 1998; 33:1498-500. doi: 10.1016/S0022-3468(98)90484-5.

2. Sandoval C, Stringel G, Ozkaynak MF, Tugal O, Jayabose S. Laparoscopic splenectomy in pediatric patients with hematologic diseases. JSLS 2000; 4:117-20.

3. Murawski M, Patkowski D, Korlacki W, Czauderna P, Sroka M, Makarewicz W, et al. Laparoscopic splenectomy in children: A multicenter experience. J Pediatr Surg 2008; 43:951-4. doi: 10.1016/j.jpedsurg.2007.11.040.

4. Vargün R, Göllü G, Fitöz S, Yagmurlu A. En-bloc stapling of the splenic hilum in laparoscopic splenectomy. Minim Invasive Ther Allied Technol 2007; 16:360-2. doi: 10.1080/ 13645700701699414

5. Bhatti KM, Alsibai SM, Albalushi ZN, Alisaee AS,
Almasrouri SM. Current status of pediatric minimal access surgery at Sultan Qaboos University Hospital: A 3-year experience. Ann Pediatr Surg 2013; 9:140-3. doi: 10.1097/01. XPS.0000434487.93877.be.

6. El-Hazmi MA, Al-Hazmi AM, Warsy AS. Sickle cell disease in Middle East Arab countries. Indian J Med Res 2011; 134:597-610. doi: 10.4103/0971-5916.90984.

7. Al-Riyami AA, Suleiman AJ, Afifi M, Al-Lamki ZM, Daar S. A community-based study of common hereditary blood disorders in Oman. East Mediterr Health J 2001; 7:1004-11.

8. Al-Riyami A, Ebrahim GJ. Genetic blood disorders survey in the Sultanate of Oman. J Trop Pediatr 2003; 49:11-20.

9. Bonnard A, Masmoudi M, Boimond B, Capito C, Holvoet L, Skhiri A, et al. Acute chest syndrome after laparoscopic splenectomy in children with sickle cell disease: Operative time dependent? Pediatr Surg Int 2014; 30:1117-20. doi: 10.1007/ s00383-014-3600-0.

10. Brousse V, Buffet P, Rees D. The spleen and sickle cell disease: The sick(led) spleen. Br J Haematol 2014; 166:165-76. doi: 10.1111/bjh.12950.

11. Machado NO, Grant CS, Alkindi S, Daar S, Al-Kindy N, Al Lamki Z, et al. Splenectomy for haematological disorders: A single center study in 150 patients from Oman. Int J Surg 2009; 7:476-81. doi: 10.1016/j.ijsu.2009.08.004.

12. Rice HE, Crary SE, Langer JC, Kemper AR; Splenectomy in Congenital Hemolytic Anemia Consortium. Comparative effectiveness of different types of splenectomy for children with congenital hemolytic anemias. J Pediatr 2012; 160:684-9. doi: 10.1016/j.jpeds.2011.09.030.

13. Al-Salem AH. Indications and complications of splenectomy for children with sickle cell disease. J Pediatr Surg 2006; 41:1909-15. doi: 10.1016/j.jpedsurg.2006.06.020.

14. Englum BR, Rothman J, Leonard S, Reiter A, Thornburg C, Brindle $M$, et al. Hematologic outcomes after total splenectomy and partial splenectomy for congenital hemolytic anemia. J Pediatr Surg 2016; 51:122-7. doi: 10.1016/j.jped surg.2015.10.028

15. Esposito C, Corcione F, Garipoli V, Ascione G. Pediatric laparoscopic splenectomy: Are there real advantages in comparison with the traditional open approach? Pediatr Surg Int 1997; 12:509-10. doi: 10.1007/BF01258713.

16. Al-Salem AH. Splenic complications of sickle cell anemia and the role of splenectomy. ISRN Hematol 2011; 2011:864257. doi: $10.5402 / 2011 / 864257$.

17. Meshikhes AW, Mubarek MA, Abu-Alrahi AI, Al-Saif OH. The pattern of indications and complications of splenectomy in Eastern Saudi Arabia. Saudi Med J 2004; 25:1892-5.

18. Schaarschmidt K, Kolberg-Schwerdt A, Lempe M, Saxena A. Ultrasonic shear coagulation of main hilar vessels: A 4-year experience of 23 pediatric laparoscopic splenectomies without staples. J Pediatr Surg 2002; 37:614-16. doi: 10.1053/ jpsu.2002.31620.

19. de Lagausie P, Bonnard A, Benkerrou M, Rorlich P, de Ribier A, Aigrain Y. Pediatric laparoscopic splenectomy: Benefits of the anterior approach. Surg Endosc 2004; 18:80-2. doi: 10.1007/ s00464-003-9048-2.

20. Romano F, Caprotti R, Franciosi C, De Fina S, Colombo G, Sartori P, et al. The use of LigaSure during pediatric laparoscopic splenectomy: A preliminary report. Pediatr Surg Int 2003; 19:721-4. doi: 10.1007/s00383-003-1037-y.

21. Cusick RA, Waldhausen JH. The learning curve associated with pediatric laparoscopic splenectomy. Am J Surg 2001; 181:393-7. doi: 10.1016/S0002-9610(01)00609-2. 